biologically plausible as a known TGF- $\beta$ target gene. The results presented in the current paper emphasise the potential utility of this approach for target identification in diseases of unknown aetiology.

Competing interests: None.

Thorax 2009;64:461-462. doi:10.1136/thx.2008.110577

\section{REFERENCES}

1. Selman M, King TE, Pardo A. Idiopathic pulmonary fibrosis: prevailing and evolving hypotheses about its pathogenesis and implications for therapy. Ann Intern Med 2001;134:136-51.

2. Thannickal VJ, Horowitz JC. Evolving concepts of apoptosis in idiopathic pulmonary fibrosis. Proc Am Thorac Soc 2006;3:350-6.

3. Kuwano K, Kunitake R, Maeyama T, et al. Attenuation of bleomycin-induced pneumopathy in mice by a caspase inhibitor. Am J Physiol 2001;280:L316-25.
4. Kuwano K, Hagimoto N, Kawasaki M, et al. Essential roles of the fas-fas ligand pathway in the development of pulmonary fibrosis. J Clin Invest 1999:104:13-9.

5. Maeyama T, Kuwano K, Kawasaki M, et al. Upregulation of Fas-signalling molecules in lung epithelial cells from patients with idiopathic pulmonary fibrosis. Eur Respir J 2001;17:180-9.

6. Korfei M, Ruppert C, Mahavadi P, et al. Epithelial endoplasmic reticulum stress and apoptosis in sporadic idiopathic pulmonary fibrosis. Am J Respir Crit Care Med 2008;178:838-46.

7. Oikonomou N, Thanasopoulou A, Tzouvelekis A, et al. Gelsolin expression is necessary for the development of modelled pulmonary inflammation and fibrosis. Thorax 2009;64:467-75.

8. Witke W, Sharpe AH, Hartwig JH, et al. Hemostatic inflammatory, and fibroblast responses are blunted in mice lacking gelsolin. Cell 1995;81:41-51.

9. Kothakota S, Azuma T, Reinhard C, et al. Caspase-3generated fragment of gelsolin: effector of morphological change in apoptosis. Science 1997;278:294-8.
10. Walsh JG, Cullen SP, Sheridan C, et al. Executioner caspase-3 and caspase-7 are functionally distinct proteases. Proc Natl Acad Sci U S A 2008;105:12815-9.

11. Becker PM, Kazi AA, Wadgaonkar R, et al. Pulmonary vascular permeability and ischemic injury in gelsolin-deficient mice. Am J Respir Cell Mol Biol 2003;28:478-84.

12. Yildirim F, Gertz K, Kronenberg G, et al. Inhibition of histone deacetylation protects wildtype but not gelsolin-deficient mice from ischemic brain injury. Exp Neurol 2008;210:531-42.

13. Leifeld L, Fink K, Debska G, et al. Anti-apoptotic function of gelsolin in fas antibody-induced liver failure in vivo. Am J Pathol 2006:168:778-85.

14. Kinder BW, Brown KK, Schwarz MI, et al. Baseline $\mathrm{BAL}$ neutrophilia predicts early mortality in idiopathic pulmonary fibrosis. Chest 2008;133:226-32.

15. Tzouvelekis A, Harokopos V, Paparountas T, et al. Comparative expression profiling in pulmonary fibrosis suggests a role of hypoxia-inducible factor-1alpha in disease pathogenesis. Am J Respir Crit Care Med 2007:176:1108-19.

\title{
Has ISAAC told us as much as it can? Where now?
}

\section{Martyn R Partridge}

Readers of a certain age may recall the use of diets in the management of peptic ulcer disease, their replacement by the introduction of increasingly complicated surgery such as highly selective vagotomy, and the subsequent discovery of the critical role of Helicobacter pylori infection in the causation of this (and other) diseases. What will the denouement for asthma be in 5,10 or 15 years?

The output of the International Study of Asthma and Allergies in Childhood (ISAAC) over the last 14-15 years has told us a lot. ${ }^{1-3}$ We now know that the prevalence of wheeze in the past 12 months amongst both 6- to 7-year-old and 13- to 14-year-old children varies only a little within countries but widely between countries. In the countries which have taken part in sequential phases of ISAAC, we know that in some the prevalence continues to rise, in others it has plateaued, whilst in others the number of affected children has fallen over a decade. The latest ISAAC report (see page 476) further contributes to this knowledge by informing us of data from a further 128 new centres. ${ }^{4}$ The results again demonstrate rates of current wheeze that, for example, vary from a third of New Zealand 13- to 14-year-old

Correspondence to: Professor Martyn R Partridge, Imperial College London, NHLI Division at Charing Cross Hospital, St Dunstan's Road, London W6 8RP, UK; m.partridge@imperial.ac.uk children having a current wheeze to $<1 \%$ responding positively to this question in Tibet. Trends in the "new" countries are in general similar to those shown in 1997, with the highest rates being in English language countries and South America, higher rates in Western than Eastern Europe, and lower prevalence in Africa and Asia. However, there is considerable heterogeneity in rates within some regions, with Mexico having rates much lower than the rest of South America, and Sri Lanka having rates higher than many other parts of Asia. In an attempt to explain these differences the authors have looked at one variable, economic development, and demonstrated higher prevalence in more affluent countries, but interestingly also noted that whilst overall prevalence was lower in countries with lower incomes, the severity might have been higher. They speculate that this could reflect lower understanding of the significance of wheeze as a marker of asthma in those countries, but also speculate that it might reflect either less good asthma care or a more adverse environment in these countries. The previous ISAAC time trends paper ${ }^{3}$ also necessitates speculative interpretation. That some countries experience a rise in prevalence a few years later than occurred in other countries is perhaps not difficult to comprehend. The fact that other countries experience a plateauing of prevalence is similarly interesting, comprehensible and encouraging. That others have experienced a decline in prevalence over a 10-year period is much harder to explain. The ISAAC team cannot really help us here and have suggested that whilst treatment may affect severity it would not have affected prevalence. Whether that interpretation is correct if the questions relate to wheezing is debatable, and others have studied and queried the effects of treatment, repeated questioning of children and thresholds for diagnostic labels on studies of prevalence. ${ }^{56}$

ISAAC has been an extraordinary epidemiological study carried out with rigour and enthusiasm. It has told us much, and as with any study one can speculate as to the accuracy of parts of the data, and the authors repetitively discuss methodology and statistical pitfalls in their reports. However, there can be little doubt from ISAAC and from other studies of prevalence done using the same methodologies amongst the same aged children in the same places at different times, ${ }^{7-9}$ that in many countries the prevalence of this condition has, at least until recently, increased dramatically. However, we do not yet have a preventive strategy such that we can advise either individuals or governments how they might reduce the chance of children being born with this condition, or a tendency to it. We know that the condition will have resulted from an interaction between a susceptible host and the environment and that whilst genetic factors will play a significant part in that host susceptibility, they will not have changed over the last decade or two. Interest has therefore focused upon the interactions with the environment. Special interest and study have been focused on rates of exposure to infections in early life, to the degree of exposure to 
allergens, to the subject of both indoor and outdoor pollution and to climate change, exposure to environmental tobacco smoke and to methods of heating within the home, to diet and drug use, obesity, and to rates of caesarean sections and breast feeding. ${ }^{10-14}$ Some are hypothesis generating but none has given a comprehensive overarching explanation for a rise in prevalence.

The hypotheses have arisen from a desire to explain epidemiological differences, and those such as the "hygiene" hypothesis had a seemingly corroboratory immunological explanation. ${ }^{15}$ However, they have not taken us to the point where we can proudly announce a primary preventive strategy. This is likely to involve a multipronged approach. Answers are only likely to result from greater study of high risk infants where the study participants are carefully phenotyped, there are few drop outs, tight observation on environmental factors including exposure to infections, and prolonged follow-up. Other studies have identified genetic markers of susceptibility to asthma and been followed by studies that better characterise the clinical risk of such genetic susceptibilities. ${ }^{16}$ The peptic ulcer story may have relevance to asthma and, after early interest in the importance of respiratory syncytial viruses and subsequent excitement at the possible role of Mycoplasma pneumoniae, ${ }^{17}$ we need to recognise that it may be many bacteria that play a part and that some may be protective, some may be aetiologically significant, and that the timing of such infections in the newborn's life may be the critical factor. ${ }^{18}$ Parallel studies are then needed to see whether other genotypic variants inter-react with, for example, air pollution to enhance risk and how this is influenced by exposure to allergens and infections. ${ }^{19}$

We cannot afford to wait another 10 or 20 years for our preventive strategy in asthma. ISAAC has demonstrated the challenge, and large well-funded cohort studies linked to good laboratory documentation of infections, followed hopefully by intervention studies, are needed. In asthma we are far ahead of the diet stage, for we do of course have treatment capable of fully controlling asthma for the majority. However, for the individual and for nations, not developing the disease in the first place would be infinitely preferable. There is a danger that the very effectiveness of treatment reduces the burden to the extent that the funding and impetus to research causation might lessen. That must not be allowed to happen.

Competing interests: None.

Thorax 2009;64:462-463. doi:10.1136/thx.2008.114157

\section{REFERENCES}

1. Asher MI, Keil U, Anderson HR, et al. International Study of Asthma and Allergies in Childhood (ISAAC): rationale and methods. Eur Respir J 1995;8:483-91.

2. Beasley R, Keil U, Von Mutius E, et al. Worldwide variation in prevalence of symptoms of asthma, allergic rhinoconjunctivitis and atopic eczema: ISAAC Lancet 1998;351:1225-32.

3. Pearce N, At-Khaled N, Beasley R, et al. Worldwide trends in the prevalence of asthma symptoms: phase III of the International Study of Asthma and Allergies in Childhood (ISAAC). Thorax 2007;62:758-66.

4. Lai CKW, Beasley R, Crane J, et al. Global variation in the prevalence and severity of asthma symptoms: phase three of the International Study of Asthma and Allergies in Childhood (ISAAC). Thorax 2009;64:476-83.

5. Sears MR, Lewis S, Herbison GP, et al. Comparison of reported prevalences of recent asthma in longitudinal and cross-sectional studies. Eur Respir $J$ 1997:10:51-4

6. Chinn S, Jarvis D, Burney P, et al. Increase in diagnosed asthma but not symptoms in the European Community Respiratory Health Survey. Thorax 2004;59:646-51.

7. Ninan TK, Russell G. Respiratory symptoms and atopy in Aberdeen schoolchildren: evidence from two surveys 25 years apart. BMJ 1992;304:1157.

8. Burr ML, Butland BK, King $\mathrm{S}$, et al. Changes in asthma prevalence: two surveys 15 years apart. Arch Dis Child 1989;64:1452-6.

9. Rona RJ, Chinn S, Burney PG. Trends in the prevalence of asthma in Scottish and English primary school children 1982-92. Thorax 1995;50:992-3.

10. Lewis S, Butland B, Strachan D, et al. Study of aetiology of wheezing illness at age 16 in two national British birth cohorts. Thorax 1996;51:670-6.

11. Roduit C, Scholtens S, de Jongste JC, et al. Asthma at 8 years of age in children born by caesarean section. Thorax 2009;64:107-13.

12. Shaheen So, Sterne JAC, Songhurst CE, et al. Frequent paracetamol use and asthma in adults. Thorax 2000;55:266-70.

13. Oddy WH, Sherriff JL, de Klerk NH, et al. The relation of breastfeeding and body mass index to asthma and atopy in children: a prospective cohort study to age 6 years. Am J Pub Health 2004;94:1531-7.

14. Chinn S, Rona RJ. Can the increase in body mass index explain the rising trend in asthma in children. Thorax 2001;56:845-50.

15. Strachan DP. Hay fever, hygiene, and household size. BMJ 1989;299:1259-60.

16. Bisgaard H, BØnnelykke K, Sleiman PMA, et al. Chromosome 17q21 gene variants are associated with asthma and exacerbations but not atopy in early childhood. Am J Respir Crit Care Med 2009;179:179-85.

17. Yano T, Ichikawa Y, Komatu S, et al. Association of Mycoplasma pneumonia antigen with initial onset of bronchial asthma. Am J Respir Crit Care Med 1994;149:1348-53.

18. Bisgaard $\mathbf{H}$, Hermansen MN, Buchvald F, et al. Childhood asthma after bacterial colonization of the airway in neonates. $N$ Engl $\mathrm{J}$ Med 2007;357:1487-95.

19. Salam MY, Lin P-L, Avol E, et al. Microsomal epoxide hydrolase, glutathione S-transferase P1, traffic and childhood asthma. Thorax 2007;62:1050-7.

\section{Unintended consequences in the drive for zero}

\section{Michael Klompas}

With pressure mounting from legislators, insurers and consumer advocates to drive ventilator-associated pneumonia (VAP) rates to zero, the article by Conway Morris and colleagues (see page 516) in this issue of Thorax is a timely reminder

Correspondence to: Dr Michael Klompas, Department of Ambulatory Care and Prevention, Harvard Medical School and Harvard Pilgrim Health Care, 133 Brookline Avenue, 6th Floor, Boston, MA 02215, USA;

mklompas@partners.org that VAP rates are uncertain estimates rather than concrete measures of patient morbidity. ${ }^{1}$ Conway Morris and colleagues show that the reported VAP rate of an Intensive Care Unit (ICU) is heavily dependent upon its favoured diagnostic technique. ICUs that exclusively use bronchoalveolar lavage (BAL) to diagnose $\mathrm{VAP}$ are liable to report VAP rates that are $76 \%$ lower than those that exclusively use endotracheal aspirates. This laxity in the VAP definition confers a risk that some well-intended initiatives may decrease VAP rates yet provide little benefit to patients and perhaps even put some at risk.

Conway Morris and colleagues base their estimate of varying VAP rates upon the comparative yield of simultaneous BAL and endotracheal aspirate cultures taken from 53 critically ill patients with clinical syndromes suggestive of pneumonia. All patients had radiographic infiltrates, pyrexia or an abnormal leucocyte count, and clinical signs of chest infection such as increased volume or purulence of sputum, crepitations and deterioration in oxygenation. In these patients, there was a clear step function in culture results: $89 \%$ of endotracheal aspirate qualitative cultures were positive (defined as any growth), $51 \%$ of endotracheal quantitative 